\title{
Prospects and Challenges of Thermal Energy Storage in Future Energy Systems
}

\author{
Stefan Holler, University of Applied Sciences and Arts
}

\begin{abstract}
As a result of European energy and climate policy a growing share of renewable energy can be noted in European energy markets. Especially in the electricity market this leads to a higher volatility of the electricity price. In an open market this highly affects the share of cogeneration that is generally linked to local or district heating systems. The integration of thermal energy storage in district heating systems with cogeneration increases the flexibility of operation and thus maintains the profitability of combined heat and power units.

In this paper a power-to-heat concept is proposed that offers additional benefits for thermal energy storage when electricity generation from renewable energy sources exceeds the current demand. The concept is analyzed from a technological and economic perspective.
\end{abstract}

Keywords -district heating, electrode boiler, renewable energy, thermal energy storage

\section{INTRODUCTION}

Conservation of energy is well known in the energy sector and different technologies are state of the art and well established within the market. Nevertheless, storing of energy gets growing importance nowadays, as energy systems are being transformed in order to replace fossil fuels by renewable energy sources. As renewable energy sources, such as wind or solar energy, are fluctuating over time it is necessary to increase the flexibility of energy systems in order to compensate for the mismatch between energy generation and energy demand of customers [1]. Hereby, energy storage offers a wide variety of possibilities. Previous studies show prospects and challenges of thermal energy storage when integrated into district heating systems with a high share of cogeneration.

In [2] a model has been presented that determines the theoretical maximum of flexibility of a combined heat and power system coupled to a thermal energy storage solution that can be either centralized or decentralized. In that study, the amount of flexibility created in the district heating system is determined by the approach of the system through delayed or forced operation mode. It was found that the distinction between the implementation of the thermal energy storage as a central unit or as a collection of local units has a dramatic effect on the amount of available flexibility. The study confirms that centrally located storage offers more flexibility compared to individual units.

Among the large variety of energy storage solutions, which are available on the market or are subject to current research and development projects, this study focuses on the prospects and challenges of thermal energy storage. Furthermore this study especially outlines the application of stratified hot water storages and their integration into district heating systems.
Different technologies for heat conservation are available, depending of technical principle, storing period and storage geometry. A good introduction and extended overview is given in [3]. According to the functional principle thermal energy storage is generally divided into sensible, latent or thermochemical heat storage. Stratified hot water storages that are being analysed in this study, belong to the category of sensible heat storage. They are characterised by a wide range of applications and sizes. Stratified hot water storages are used in small scale within building heating systems as well as in large scale within local or district heating systems, when it is necessary to uncouple heat generation from heat demand. Heat accumulation in local or district heating systems is used either when the heat source itself is fluctuating, as it is the case in solar thermal systems, or when economic boundary conditions require a higher flexibility for energy generation, as it is the case in systems with cogeneration.

Cogeneration is the combined generation of heat and power (CHP) in a single unit, and it is characterized by an efficient use of primary energy. Modern CHP plants have an utilisation ratio as high as $85-90 \%$ [4]. However, as heat and power generation are coupled, the profitability of a CHP unit depends very much on the demand, respectively the market price of both energy forms - electricity and heat.

Figure 1 illustrates the mismatch of thermal and electrical energy demand for a municipal supply system for a typical year. The load curves for heat and electricity are differing throughout the year. Thus, during summer months there is a high surplus of thermal energy when electricity is generated in cogeneration units.

Without thermal energy storage, a CHP unit would be in operation as long as heat demand and electricity demand exists.

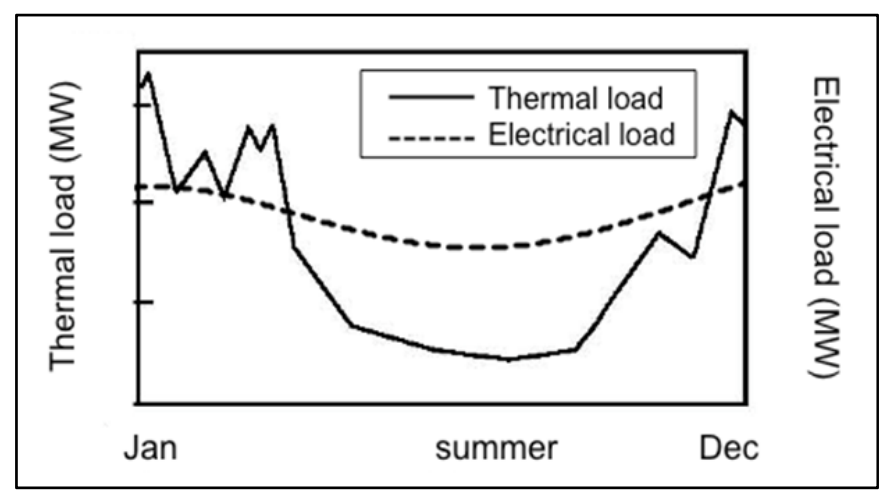

Fig. 1. Typical load curves of heat and electricity demand for a municipal supply system over the year. 
$2013 / 3$

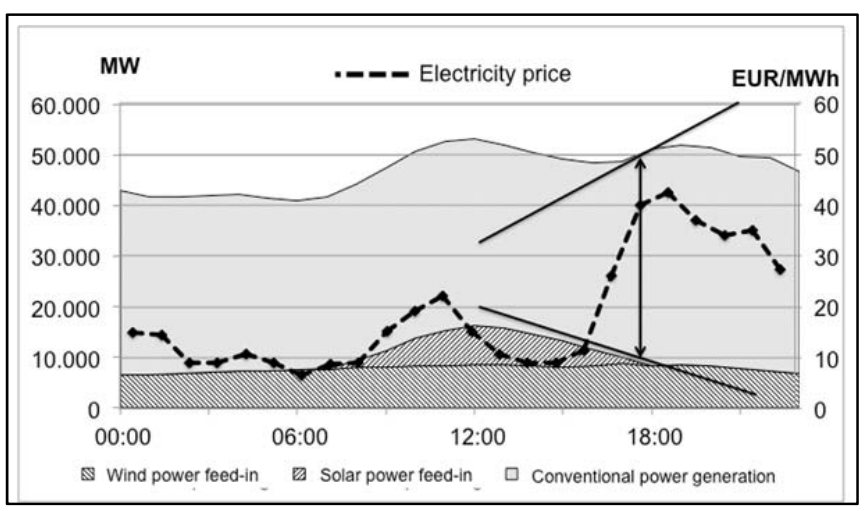

Fig. 2. Electricity price fluctuates on a characteristic weekend day in March 2013. Electricity feed-in from wind power and photovoltaic plants deliver the base load. Conventional generation in fossil power plants covers the remaining demand. Data of European Electricity Index (ELIX) from 10.3.2013 are taken from European Energy Exchange (EEX) [5].

As soon as the electricity demand decreases and the price drops below the marginal price for the given CHP unit, a heatonly boiler will be operated instead to cover the heat demand of the supply system. In times of low heat demand and high electricity demand, the CHP unit can be operated from the economic point of view; however, the cogenerated heat would then be wasted.

In [6] a methodology is proposed for the evaluation of large district heating systems with cogeneration in order to avoid the waste of heat. Using data from the large-scale Tallinn district heating system, it is shown that an effective operation of cogeneration plants could decrease the consumption of primary energy in the system.

Furthermore, thermal energy storage offers the chance for extended CHP operation according to the electricity market price without wasting the by-product heat. At times of low heat demand, the thermal energy storage will be charged. The accumulated thermal energy is then used to cover the peak load of the heating system in times of higher heat demand or when the CHP unit is not in operation. As an additional benefit, this operation mode of a CHP unit with heat accumulation enables longer annual operation times of the cogeneration unit and reduces the inefficient use of heat-only boilers for peak load coverage. The use of storage systems in district heating at the example of the Turin district heating system is evaluated in [7]. A multi-scale model of a storage tank is proposed, and the results of that case study show that primary energy consumption could be reduced up to $12 \%$.

The economic potential of heat accumulators within the power plant park of Berlin is analyzed in [8]. The authors conclude that partially decoupling the production of heat in CHP units from the demand of a district heating network leads to lucrative payback periods for storage devices in the considered energy system.

The increasing percentage of renewable energy in the electricity market results in a high volatility of the electricity price, which strongly affects the operation of cogeneration units. Figure 2 illustrates exemplarily the fluctuating daily electricity price for a characteristic day on the weekend. During daytime, when the supply of solar feed-in through photovoltaic units is high, the price is low. In the evening, the share of renewable feed-in decreases while at same time the demand increases. It can be noted that in this situation the electricity price is rising. This effect results from the need of more balance energy that is only available at a higher price.

As described above, cogeneration is only profitable at an electricity price above a certain marginal value. Otherwise the CHP unit would operate in a non-profitable range. Instead of operating fossil fuelled peak-load boilers in this situation, it is proposed to integrate electrode boilers into the heating system. The use of an electrode boiler has two main advantages. On the one hand, it uses electricity from renewable energy generation such as photovoltaic or wind power units, and on the other hand, it can compensate for the necessary heat supply of the local or district heating system, or it can be used to charge the thermal energy storage. This, so-called power-to-heat concept has been analysed in this study from a technological and economic perspective.

\section{THE POWER-TO-HEAT CONCEPT}

Due to an increasing share of renewable energy in the electricity market, the technological concept of power-to-heat gains grows in attractiveness at utilities [9]. The concept offers interesting perspectives to increase energy efficiency, especially for district heating systems with cogeneration units.

Figures 3 and 4 schematically illustrate how the electricity and heat demand of customers will be covered in a typical supply system with district or local heating. The flow charts show the situation without (Figure 3) and with (Figure 4) increased renewable electricity generation.

In the first scenario (Figure 3), the electricity demand is covered by a combination of decentralized cogeneration and conventional power plants, whereas cogenerated electricity has a higher priority than conventionally generated electricity. In several European countries corresponding laws regulate this priority feed-in. An overview is given in [10]. That study assesses the strength and effectiveness of renewable electricity feed-in tariffs in European Union countries.

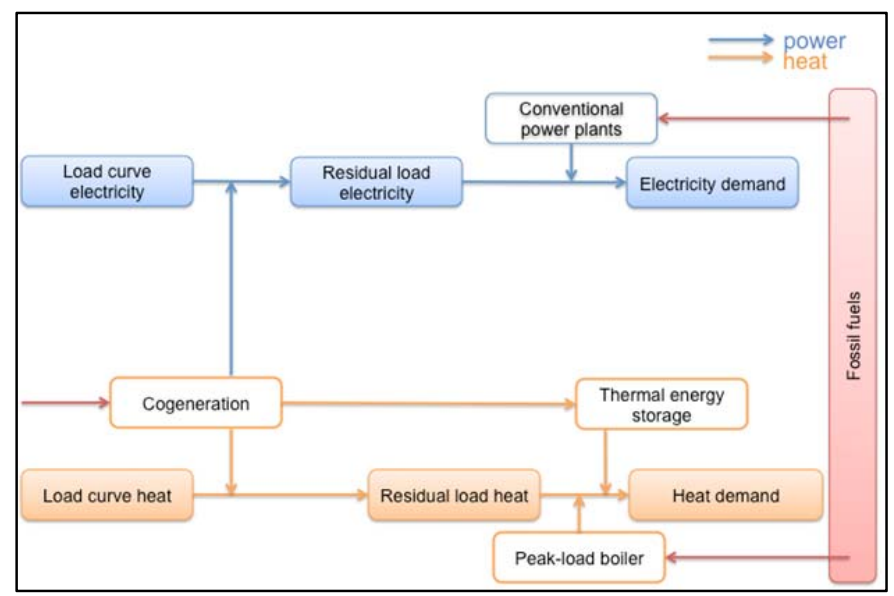

Fig. 3. Scenario of a supply system with cogeneration and thermal energy storage: CHP unit and peak-load boiler cover the heat demand. CHP unit and residual electricity from the grid cover the electricity demand. 


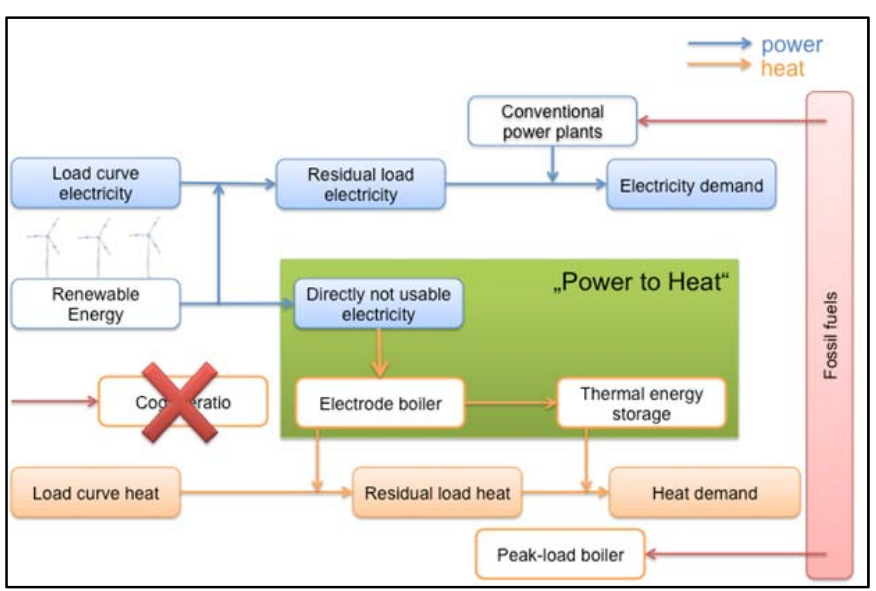

Fig. 4. Scenario of the power-to-heat concept: When a surplus of renewable energy is available on the market, CHP unit and peak-load boiler will be shut down. Heat storage and electrode boiler cover the heat demand.

Local heat generation units either through cogeneration or through heat-only boilers cover the heat demand. Cogeneration units are used for the base load and peak-load boilers cover the residual load of the demand curve. Peak-load boilers have generally only low operation times, and they are normally fired by fossil fuels. If thermal energy storage is available, the share of cogeneration can be increased, as surplus heat is stored in times of low heat demand. At times of high electricity prices the storage is discharged, again. Thus, the overall share of cogeneration increases, and the operation time for the peak-load boiler decreases.

Figure 4 illustrates the power-to-heat concept at which a surplus of renewable energy is stored in the heating system at times of low electricity demand. Recent experiences from the European electricity market show that at times when a lot of renewable energy is generated the electricity price on the spot market drops and cogeneration might not be cost-effective. For this situation, the necessary heat is either taken from the thermal energy storage or is generated by an electrode boiler. Alternatively heat pumps can be used. A positive side effect is that the operation time of the fossil peak-load boiler is reduced, thus lowering fossil fuel consumption and $\mathrm{CO}_{2}$ emissions. Thus, electrode boilers enable conservation of surplus energy from renewable energy generation.

\section{ECONOMIC EVALUATION}

An economic analysis has been made for the use of an electrode boiler as shown in Figure 4 and as described above. The following assumption and premises have been made for the economic calculations:

The scenario of a supply system has been analysed at which an electrode boiler with capacity $P_{e l, E B}$ is installed and replaces a cogeneration unit of same capacity $P_{e l, C H P}$ when the electricity price $p_{e l}$ is low. For the base scenario, the marginal electricity price of $p_{e l}=10 \mathrm{EUR} / \mathrm{MWh}$ was determined.

\section{A. Calculation of cost saving}

The scenario applies from the economic perspective when the saving of annual operation costs $\Delta C$ due to reduced fuel demand of the cogeneration unit compensates the annuity of investment costs $a_{E B}$ of the electrode boiler. The annuity of the electrode boiler is calculated according to the financial data listed in Table I.

TABLE I

CALCUlation of ANNUity FOR Electrode Boiler (1MW)

\begin{tabular}{|l|c|c|c|}
\hline Investment costs & & 90.000 & EUR \\
\hline Interest rate & & 6 & $\%$ \\
\hline Amortisation period & & 20 & Years \\
\hline Annuity & $\boldsymbol{a}_{E B}$ & 7.850 & EUR \\
\hline
\end{tabular}

Thus, for the normed annual operation costs results

$$
\frac{\Delta C}{a_{E B}}=1 \text {. }
$$

$\triangle C$ is calculated according to (2), covering the saved fuel heat $\Delta W_{f u, C H P}$ and the lost electricity generation $\Delta E_{C H P}$ of the cogeneration unit as well as the electricity consumption of the electrode boiler $E_{E B}$ with energy prices of fuel $p_{f u}$ and electricity $p_{e l}$.

$$
\Delta C=\Delta W_{f u, C H P} \cdot p_{f u}-\left(\Delta E_{C H P}+E_{E B}\right) \cdot p_{e l}
$$

In (2) the assumption has been made that the feed-in tariff for electricity from cogeneration equals the price of electricity purchased for the electrode boiler. For the purpose of this study the simplification is justified, as a general understanding of the economic situation should be established. However, in real markets additional price components have to be taken into account. $\Delta W_{f u, C H P}$ is linked to $\Delta E_{C H P}$ by the electrical utilisation ratio $\zeta_{e l}$.

$$
\varsigma_{e l}=\frac{\Delta E_{C H P}}{\Delta W_{f u, C H P}}
$$

The marginal operation time $t_{o p, E B}$ of the electrode boiler equals the time when the cogeneration unit is shut down, and it can be calculated according to (4).

$$
t_{o p, E B}=\frac{E_{E B}}{P_{e l, E B}}=\Delta t_{o p, C H P}=\frac{\Delta E_{C H P}}{P_{e l, C H P}}
$$

TABLE II

FINANCIAL AND TECHNICAL DATA OF BASE SCENARIO

\begin{tabular}{|l|c|c|c|}
\hline Fuel price & $p_{f u}$ & 40 & EUR/MWh \\
\hline Marginal electricity price & $p_{e l}$ & 10 & EUR/MWh \\
\hline Nominal power of electrode boiler & $P_{e l, E B}$ & 1 & $\mathrm{MW}$ \\
\hline Nominal electrical power of cogeneration unit & $P_{e l, C H P}$ & 1 & $\mathrm{MW}$ \\
\hline Electrical utilisation ratio of cogeneration unit & $\zeta_{e l}$ & 0,41 & \\
\hline
\end{tabular}

\section{B. Results}

Figure 5 shows the result of the economic analysis for the investment of an electrode boiler. In the base scenario the data 
from Table II are used to calculate cost saving in relation to the operation time of the electrode boiler. With an electricity price of $10 \mathrm{EUR} / \mathrm{MWh}$ and fuel price of $40 \mathrm{EUR} / \mathrm{MWh}$, the investment is cost-effective when an annual operation time of approximately 100 hours will be exceeded. Annual cost saving rises linearly with increasing annual operation time. When the price situation at the spot market for electricity enables an annual operation of 200 hours, the cost saving doubles. This would significantly reduce the payback time of the investment. With decreasing electricity price or increasing fuel price the break-even point, when nominal cost saving equals 1 , moves to even lower operation time.

\section{IV.DISCUSSION AND CONCLUSION}

In this study it is shown that the integration of large-scale hot water storages optimizes the energy efficiency of district heating systems with a high share of cogeneration. Furthermore, thermal energy storage increases flexibility of energy systems, as they enable the integration of electrode boilers. The technologic and economic analysis shows that electrode boilers offer an interesting option for the conservation of energy generated from renewable resources, such as wind and solar energy, at times of low electricity demand.

Previous studies, e.g. as described in [11], and the analysis of the European Electricity Index (ELIX) prove the validity of the scenario described above [5].

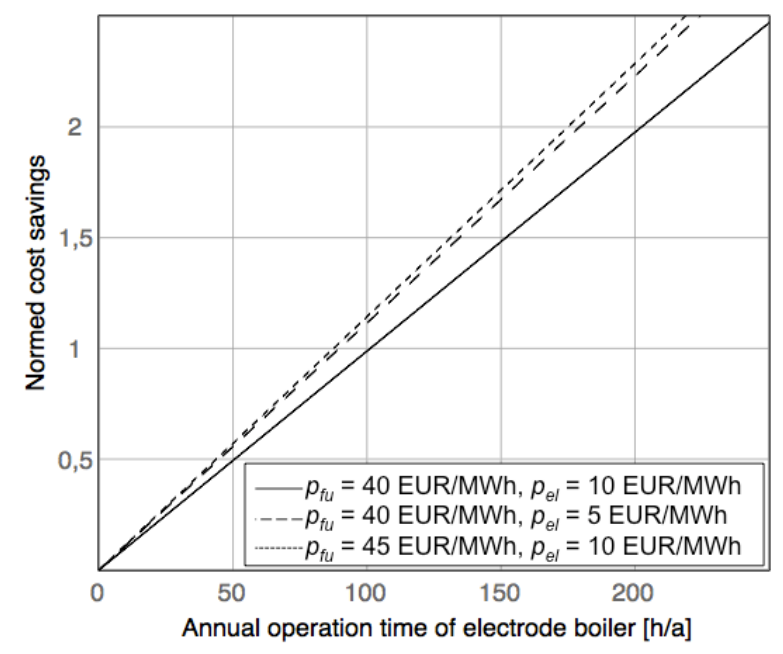

Fig. 5. Normed cost saving is plotted against annual operation time of the electrode boiler. Dotted lines show the sensitivity in respect to electricity and fuel prices.

Obviously, from a thermodynamic perspective it might be considered whether electricity should be converted into thermal energy for conservation purposes as this conversion process is irreversible and implies high exergy losses. However, it can be noted that the conversion of electrical into thermal energy only applies for the share of renewable electricity that cannot be used otherwise. In the conventional power generation process the conversion of primary energy into electrical energy is realised by several steps, and it is characterised by significant conversion losses. Wind power and photovoltaic units, however, are characterized by low conversion losses. Primary energy is converted into electrical energy either directly as in the case of photovoltaic units or via mechanical energy as in the case of wind turbines. In both cases the conversion losses are low compared to the power generation through burning of fossil fuels. Further studies are needed to evaluate the primary energy efficiency of the power-to-heat concept.

\section{REFERENCES}

1. Bewertung der Flexibilitaten von Stromerzeugungs- und KWK-Anlagen [Online]. Untersuchung im Auftrag des Bundesverbandes der Energieund Wasserwirtschaft e. V. (BDEW), durchgeführt von Consentec und IAEW, Berlin, 2011, p. 21 [Accessed 19.09.2013.]. Available: info@consentec.de - www.consentec.de

2. Nuytten, T., Claessens, B., Paredis, K., et al. Flexibility of a combined heat and power system with thermal energy storage for district heating. Applied Energy, 2013, vol. 104, p. 583-591. http://dx.doi.org/10.1016/j.apenergy.2012.11.029

3. Dincer, I., Rosen, M. Thermal Energy Storage: systems and applications. 2. ed., Chichester: Wiley, 2011.

4. Pilavachi, P.A. Power generation with gas turbine systems and combined heat and power. Applied Thermal Engineering, 2000, vol. 20, p. 1421-1429. http://dx.doi.org/10.1016/S1359-4311(00)00016-8

5. EEX (European Energy Exchange). [Online]. 2011- [Accessed 19.09.2013.]. Available: http://www.transparency.eex.com/de/

6. Volkova, A., Mashatin, V., Hlebnikov, A., et al. Methodology for the Improvement of Large District Heating Networks. Environmental and Climate Technologies, 2013, vol 10, N 1, p. 39-45.

7. Verda, V., Colella, F. Primary energy saving through thermal storage in district heating networks. Energy, 2011, vol. 36, N 7, p. 4278-4286. http://dx.doi.org/10.1016/j.energy.2011.04.015

8. Christidis, A., Koch, C., Pottel, L., et al. The contribution of heat storage to the profitable operation of combined heat and power plants in liberalized electricity markets. Energy, 2012, vol. 41, N 1, p. 75-82. http://dx.doi.org/10.1016/j.energy.2011.06.048

9. Groscurth, H., Bode, S. Discussion Paper Nr. 9 "Power-to-heat" oder "Power-to-gas"? [Online]. arrhenius Institut für Energie- und Klimapolitik, Hamburg, 2013- [Accessed 19.09.2013.] Available:

info@arrhenius.de - www.arrhenius.de

10. Jenner, S., Groba, F., Indvik, J. Assessing the strength and effectiveness of renewable electricity feed-in tariffs in European Union countries. Energy Policy, 2013, vol. 52, p. 385-401. http://dx.doi.org/10.1016/j.enpol.2012.09.046

11. Wünsch, M., Thamling, N., Peter, F., et al. Beitrag von Wasrmespeichern zur Integration erneuerbarer Energien [Online]. Prognos AG, im Auftrag des AGFW, Berlin, 2011 [Accessed 19.09.2013.]. Available: www.prognos.com

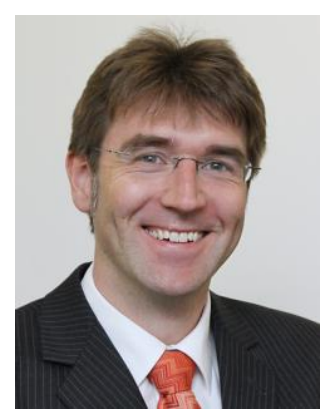

Stefan Holler, Dr.-Ing., professor, diploma in process engineering (1997) and doctoral degree (2002).

Since 2010 he is professor for energy and environmental technology at university of applied sciences and arts, Hannover. S. Holler was a manager of innovation and technology at a German utility for 10 years. Before he was employed as a researcher at German Fraunhofer Institute for Interfacial Engineering and Biotechnology. His main research interests are district heating and cooling, cogeneration and renewable energy systems.

S. Holler is vice-chairman of the European technology platform for district heating and cooling.

E-mail: stefan.holler(at)hs-hannover.de 